\title{
Research of The Combination of Production and Education In Higher Vocational Education In The Period of Economic Transition Peng HAN
}

\author{
Sichuan Information Technology College,Guangyuan,Sichuan,China,
}

628040

Keywords: higher vocational education, economic transition, combination of production and education

\begin{abstract}
With the rapid development for a decade, China's economy is switching into the stage of medium-speed development. Affected by the decline of the demand of the European and American market and the upgrade of industrial structure and other factors, China's economy will be in a new normal period of medium speed development for a long time in the future. Economic transition also has a far-reaching effect on China's higher vocational education. According to the process of the development of China's higher vocational education, this paper thoroughly analyzes the present situation and problems of the development of China's higher vocational education in the new normal period, and finally studies the measure of the combination of production and teaching that has been carried out in the development of China's higher vocational education in period of economic transition. I hope this research can provide the development of China's higher vocational education with some valuable advice, and hope that the development of China's higher vocational education has a bright future..

In recent years, with the rapid development of economy, education plays a more important role in social development. As a vital force in the development of education, higher vocational education is increasingly significant in the development of education.

The most obvious sign in the development of China's higher education is that the setting of the course in vocational and technical education is increasingly consistent with the development of socialist market economy. This makes China's higher vocational education develop along the road of occupation planning and development of socialism with Chinese characteristics.
\end{abstract}

\section{The development process of China's higher vocational and technical education}

Time flies, we have moved into the $21^{\text {st }}$ century. The history of China's education has experienced several years of ups and downs with the development of society. Throughout the history of the development of education, both brilliant period and depress period are exist. However, no matter it grows in bright light or in trouble, or grows in obscurity, the development of education shows an indomitable vitality. As an important part of the development of education, vocational education does not have history as long as basic education, or as attractive as higher education. But higher vocational education has been developing for over thirty years. It is known to all that anything cannot go smoothly. The development of higher education is no exception.

Since the explicit target of higher vocational education around the world according to the international education standard classification established by UNESCO in 1976, the development of China's higher vocational education has experienced five stages.

The first stage is from the early time of reform and opening up to the full resume of specialized education in mid 1980s. During the Cultural Revolution, not only the development of society and economy has a great setback, the development of education is extremely slow.

With the resumption of college entrance examination system in 1977, the specialized education is resumed. China implemented the policy of reform and opening up in 1978. China has a thousand things to do at that time. To meet the needs of the rapid development of society and economy after the reform and opening up , and the urgent needs of technical personnel under the social condition, a new type of college-vocational college has been created in cities with higher level of economic development. 
The second stage begins with the document on education reform issued by the Ministry of Education in 1985. This document not only first proposed the idea of positively developing the higher vocational and technical schools, but also first proposed the decision to gradually establish a vocational and technical education system. Due to the attention of central authorities, higher vocational education has been added to the national education system officially.

This results in the rapid development of vocational schools all over the nation at that time. For instance, Food Vocational School in Yibin city of Sichuan was established in 1985. The exploration period of higher vocational education is not over until mid-1990s. And the adult education was developing gradually at that time.

Therefore, vocational education at that time achieved a qualitative leap and laid the foundation for the later development.

The third stage is the establishment period of China's vocational education. This stage (1994-1998) is extremely short, but the legal status of higher vocational education was clearly defined in this stage. Higher vocational education belongs to higher education. The promulgation of "Vocational Education Law" marks the establishment of the status of higher vocational education.

The fourth stage is from 1999 to 2004, when higher vocational education was developing rapidly in a large scale. It is the golden period of the development of China's higher education. Higher vocational education has been explained no matter in the implementation of college enrollment policy or in the reform of education policy, and further clarified the fundamental task of higher education. It also makes higher vocational education develop rapidly with the support and encouragement of national policy.

The fifth stage is from 2004 to the present, higher vocational education is in the stage of enhancing the quality. In the $21^{\text {st }}$ century, with the emphasis on education and the implementation of higher education enrollment expansion policy, the development of higher vocational education entered deep water area. In order to establish a good image in the society, higher vocational education focuses on the development of the quality of vocational school students. And the cultivation of talent with high level of knowledge and culture connotations becomes the pursuit of higher vocational education.

The trend of the number of graduates of vocational education institutions from 1998 to 2004 is shown in figure 1.

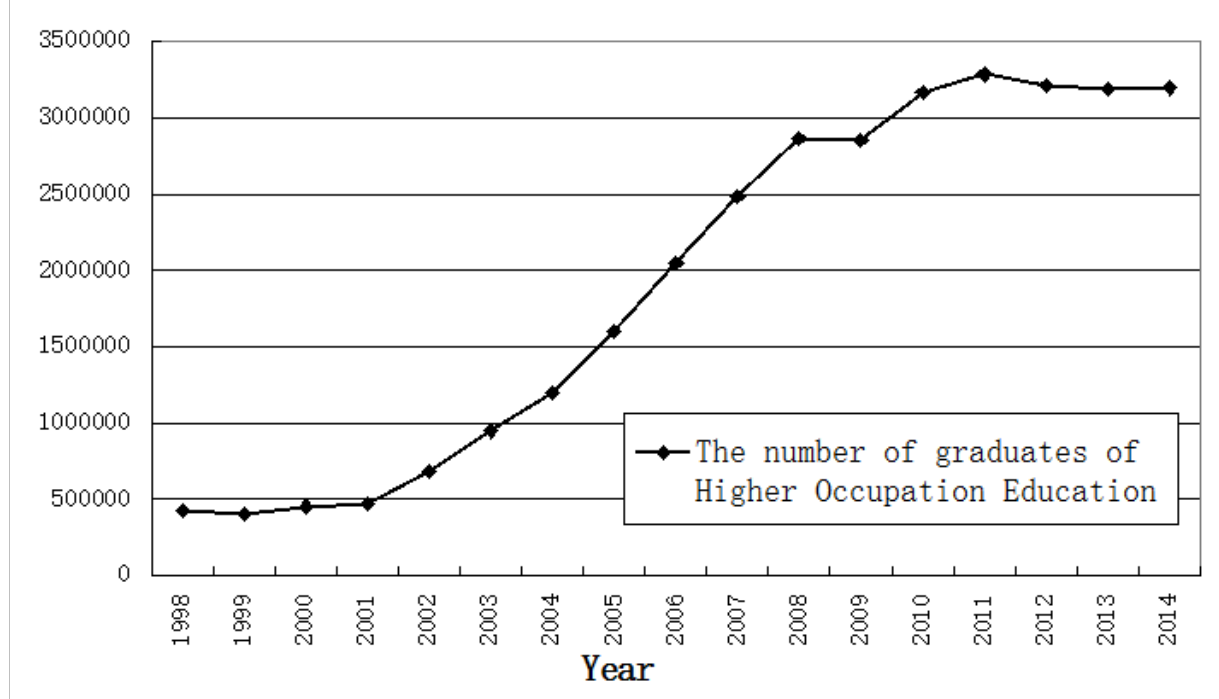

Figure 1 The trend of the number of graduates of vocational education institutions

\section{Problems in the development of higher vocational education}

In the $21^{\text {st }}$ century, the economy and technology is developing rapidly all over the world. It has been thirty years since the implementation of reform and opening up in China. The economic development is in the transition period and critical stage. 
As higher vocational education is getting attention, the development of vocational education has made remarkable achievements. For example, a large number of professional and technical personnel distributed in various social sectors made great contributions to the development of China's social economy on their front-line jobs. However, there are a series of problems that cannot be ignored in the development of higher vocational education.

\subsection{The overall quality of students is not high and problems in ideological and political education is extremely prominent}

The 21st century is the era of quality education in China. Higher vocational institution is one of the bases for the cultivation of vocational personnel. It mainly trains frontline staff to adapt to the socialized production, economic development, social management and social services. The requirements for them is the same with talents need by the modern society, the talents with advanced technical expertise and develop comprehensively in moral, intellectual, physical, aesthetic, labor and other aspects. High quality talent is not only the concentrated reflection of high moral character of contemporary college students, but also the basic quality requirements to cultivate socialist civic virtues.

However, the development of China's higher vocational education institution is not comprehensive. Students' overall quality is not high, especially their social awareness, social ethics standards and the ideological and political awareness. No matter in the campus or public places, there exists uncivilized behavior and phenomenon that does not comply with the image of contemporary college students.

After the investigation and research of several colleges in Sichuan Information Technology College etc., some common problems have been found. For instance, boys with long hair, girls keep long fingernails and dyed color, students wear vests, slippers and miniskirts on campus or in the classroom, all kinds of vulgar words filled in the campus, students surf the internet improperly and addicted to online games and so on. The rapid spread of the uncivilized phenomenon in campus is extremely bad for the development of higher vocational education. Hence, problem of ideological and political education among students is an urgent problem to be solved for China's higher vocational education.

\subsection{Students' cultural level is generally low and lack of learning ability}

It is known to all that the quality of students in higher vocational school is not so good compared to ordinary college. Students level in vocational school is complex. One third of them are from secondary vocational school. Generally speaking, most of them are losers of the college entrance exam. Thus, their basic cultural knowledge is rather weak. Other students are graduates from senior high school, vocational senior school and five-year vocational school.

Comparing with ordinary college according to the marks, these students tend to be the last level of the admissions of ordinary colleges. For example, compare the enrollment of ordinary college with higher vocational school in 2014, it can be found that the admission score of Sichuan Normal University is 520, while it is 220 in Sichuan Information Technology College.

From the instance above, it can be imagined that students of higher vocational schools are with low quality, poor learning basis, more difficulties in learning, lack of learning ability and their acceptance of professional knowledge is weak.

In addition, a series of problems exist in the process of the development of higher vocational education. Such as students' expertise is messy and unsystematic, the set of majors is not consistent with the demand of socio-economic development, the shortage of qualified teachers, the low level of teachers' overall quality, the low level of teaching and serious fault exist in school management. These issues are extremely unfavourable to the development of higher vocational education, especially in the period of the development of new normal economy, it emerges the problem such as the increase of the number of graduates of ordinary college, the adjustment of China's industrial structure, the coexistence of diverse cultures of the world and the increase of employment pressure. 
The development of higher vocational education will face more fierce competitions and challenges. Higher vocational education must take the road of combining production and education in order to survive and grow in the cracks of the development of socialist market economy.

\section{Measures of the implementation of combining production and education in higher vocational education in the period of economic transition}

At present, China is in a period of economic transition. Compared with the development of basic education and ordinary college, there is no doubt that higher vocational education is a new kind of education. The development of higher vocational education has been a hot topic concerned by educators in China. Thus, the research of higher vocational education is not as complete as other education, no matter the understanding of theory exploration or the understanding of application practice. But it is gradually mature and rational.

\subsection{Take moral education as the premise and focus on students' ideological and practical education}

On one hand, attentions should be paid to the influence of campus environment, to create a good atmoaphere in campus of vocational colleges. Campus is the main place for all kinds of activities among students. Good campus atmosphere plays an important role the regulation and guidance of students' emotions and practice. Evry part of the campus has a subtle influence on the form of students' moral behavior. The moral education in vocational college should make full use of campus to make various forms of educational activities such as value education, emotional education, civilized habits education and honesty education, to create a good atmosphere of moral civilization for students.

On the other hand, focus on the ideological and political education and reform the examination system. In all kinds of schools of modern China, politics course is setting as the obligatory course, and vocational colleges are no exception. However, in practice, students study politics only for the test, and the course does not play its due role.

Therefore, the idea of studying for the test and the original teaching method should be changed in the process of teaching. Combine the theory with the practice of students' life and fully mobilize the enthusiasm of students, so that the ideological and political course play its due role. Only by putting the moral education and ideological education in the first place can there be a training and education of professional skills for students in vocational schools. So that they not only have high practical skills but also have higher ideological and cultural quality, and stand out in the fierce competition for jobs under the social pressures to realize their life value and social value.

\subsection{Offer courses that are consistent with the socialist market economy and strenthen the communication of vocational schools and enterprises}

At present, China is in a period of economic transition. The reform and opening up has been carried out for thirty years. China's socialist market economy is greatly developed, especially after China's accession to WTO. This major initiative has a great effect on the development of China's higher vocational education, especially its providing chances of combining production with education for higher vocational education and jobs for students of vocational school. Offer courses which are consistent with the development of social economy in higher vocational education and strengthen the communication between schools and enterprises to realize the combination of production and education.

The combination of production and education refers to that schools (vocational schools) collaborate with related enterprises or departments to achieve the direct delivery of technical personnel. This teaching model is not only an inevitable trend of the socialist market economy, but also the objective requirements of the current severe employment situation. It is also an effective means of the sustainable development of higher vocational education. The teaching mode of the combination of production and education in higher vocational education under the background of market economy can strengthen the communication of schools and enterprises, which is good for the flexible adjustment of curriculum provision and training plan according to the demand of the 
development of market economy to provide a good service and technical support for economic and social development.

Therefore, under the background of market economy, the combination of production and education in higher vocational education is a new form of teaching organization with the participation of society, school and enterprise. It plays an important role in the development of higher vocational education and the development of social economy.

Besides, make positive and active guidance among students, add moral education to students' evaluation system, strengthen the education management, improve teachers' quality and professional level, strengthen the link between schools and enterprises, establish student employment service platform and broaden the channels of employment and so on. These are all approaches of the combination of production and education in higher vocational education.

All in all, higher vocational education is the inevitable requirement in a certain stage of the development of social economy. It has an unignorable effect on fostering talent and promoting employment and other aspects. With the joint efforts of the society, schools and students, in the process of higher vocational education in the future, taking the improvement of students' comprehensive quality and overall level as the premise to complete the glorious and arduous mission of cultivating highly qualified technical personnel. Only in this way can higher vocational education be more solid in the future.

\section{References}

[1] UK Department of Innovation.Business and Skills: Further Education and Skills System Reforms (an Update). . 2008

[2] JohnnySung. Vocational education and training and employer engagement: an industry - led sectoral system in the Netherlands[J]. International Journal of Training and Development . 2010 (1)

[3] NCVER.Australian vocational education and training statistics:Apprentices and trainees. Journal of Women s Health . 2007

[4] Phillip Toner,Robert Dalitz. Vocational education and training: the terra incognita of innovation policy[J]. Prometheus . 2012 (4)

[5] Susan Bandias,Don Fuller,Darius Pfitzner. Vocational and higher education in Australia: a need for closer collaboration[J]. Journal of Higher Education Policy and Management . 2011 (6) 